\title{
The anesthesia induction effect of dexmedetomidine in patients undergoing laryngeal mask intubation: a systematic review and meta-analysis of 7 RCTs
}

\author{
Qiji Ju' ${ }^{1}$ Zhibo Xiao ${ }^{2}$, Wenchao Sun ${ }^{1}$, Miao Zhu ${ }^{1}$, Peijun Lv ${ }^{1}$ \\ ${ }^{1}$ Department of Anesthesiology, Ningbo No. 6 Hospital, Ningbo, China; ${ }^{2}$ Department of Anesthesiology, The First Affiliated Hospital of Hainan \\ Medical College, Haikou, China \\ Contributions: (I) Conception and design: Q Ju; (II) Administrative support: P Lv; (III) Provision of study materials or patients: Z Xiao; (IV) Collection \\ and assembly of data: W Sun; (V) Data analysis and interpretation: M Zhu; (VI) Manuscript writing: All authors; (VII) Final approval of manuscript: \\ All authors. \\ Correspondence to: Peijun Lv. Department of Anesthesiology, Ningbo No.6 Hospital, Ningbo 315000, China. Email: jqj2324@163.com.
}

Background During laryngeal mask airway (LMA) insertion, patients need to enter a sufficient depth of sedation to prevent limb movement, coughing, laryngospasm, and other adverse reactions. This study conducted a meta-analysis to investigate the effect of dexmedetomidine on anesthesia induction in patients undergoing laryngeal mask intubation (LMI).

Methods: The Embase, PubMed, Cochrane, and Web of Science databases were searched using the keywords [Dexmedetomidine] AND [Laryngeal mask/Laryngeal mask intubation/LMI] OR [Anesthesia induction] to retrieve articles on randomized controlled trials (RCTs) in which dexmedetomidine sedation had been used in the LMI surgery. After screening the articles, the Jadad scale was used to assess the bias of the studies, and Stata16.0 software was used for the analysis to determine the anesthetic-induction effects of dexmedetomidine, fentanyl, morphine, and midazolam as sedatives.

Results: In total, 352 articles were initially retrieved, and 7 articles with a total of 410 patients were ultimately included in the meta-analysis. The effective rate of LMI induced by dexmedetomidine-assisted sedation was better than that of the control group [odds ratio $(\mathrm{OR})=1.10,95 \%$ confidence interval (CI): 0.78, 1.53], but the difference between the 2 groups was not significant $(\mathrm{Z}=0.533, \mathrm{P}=0.594)$. The respiratory rate of the dexmedetomidine group at 5 minutes after dexmedetomidine catheterization was higher than that of the control group [standardized mean difference $(\mathrm{SMD})=3.17,95 \% \mathrm{CI}: 1.38,4.96 ; \mathrm{Z}=3.476, \mathrm{P}=0.001$ ]. The heart rate of the dexmedetomidine group at 1 minute after dexmedetomidine catheterization was significantly lower than that of the control group ( $\mathrm{SMD}=-1.31,95 \% \mathrm{CI}:-1.91,-0.71 ; \mathrm{Z}=-4.255, \mathrm{P}=0.000$ ). The mean arterial pressure (MAP) of the dexmedetomidine group at 1 minute after dexmedetomidine catheterization was lower than that of the control group (SMD =-0.24, 95\% CI: $-0.94,0.45$ ), but the difference was not statistically significant $(\mathrm{Z}=-0.684, \mathrm{P}=0.494)$. The coughing count rate of the dexmedetomidine group was lower than that of the control group ( $\mathrm{OR}=0.36,95 \% \mathrm{CI}$ : $0.15,0.86 ; \mathrm{Z}=-2.286, \mathrm{P}=0.022$ )

Discussion: The application of dexmedetomidine in the anesthesia induction with LMI has a good sedative effect, improves the success rate of LMI, reduces adverse reactions.

Keywords: Dexmedetomidine; laryngeal mask tube insertion (LM tube insertion); anesthesia induction; metaanalysis

Submitted Oct 05, 2021. Accepted for publication Nov 10, 2021.

doi: 10.21037/apm-21-2971

View this article at: https://dx.doi.org/10.21037/apm-21-2971 


\section{Introduction}

Laryngeal mask $(\mathrm{LM})$ is a non-invasive ventilation device for the mouth that can seal the patient's larynx and provide positive pressure ventilation (1). LM has the advantages of both a mask and a ventilation tube, causes less irritation to the laryngeal tube and is suitable for surface and limb surgeries with shorter duration time in adults and children under general anesthesia (2). During LM airway (LMA) placement, patients are required to enter an adequate depth of sedation to prevent adverse effects, such as limb movement, coughing, choking, and laryngospasm (3). Fentanyl and carbamazepine are commonly used anestheticinduction drugs, which effectively inhibit the adverse reactions that occur during LMA catheterization. However, a study (4) has shown that fentanyl and carbamazepine may cause different degrees of respiratory and circulatory depression which is dangerous, in contrast, dexmedetomidine can provide good intubation effect during anesthesia induction without any respiratory depression. Dexmedetomidine is a highly selective $\alpha 2$ adrenoceptor agonist with sedative and analgesic properties (5). The influence of dexmedetomidine on hemodynamics is very complex. Due to the sedative effect of dexmedetomidine, it can resist central nervous sympathetic excitation, so it can reduce the patient's heart rate and mean arterial pressure (MAP). However, dexmedetomidine can also activate peripheral $\alpha 2$ adrenoceptors, which may lead to the increase of MAP $(6,7)$. This study conducted a meta-analysis to compare the effects of dexmedetomidine and other sedatives in the induction of anesthesia in patients intubated with a LMA, and provided a comparison of the effects on hemodynamics.

We present the following article in accordance with the PRISMA reporting checklist (available at https://dx.doi. org/10.21037/apm-21-2971).

\section{Methods}

\section{Research data}

\section{Inclusion criteria}

To be eligible for inclusion in the meta-analysis, articles had to meet the following inclusion criteria:

(I) Study type: be a randomized controlled trial (RCT) published in the English language;

(II) Study subjects: patients included should all be awake during LMI, and have an ASA (American Society of Anesthesiologists) grade I-III, no gastroesophageal reflux disease, no anesthetic drug allergy, no coagulation disorder, no hypertension, no diabetes, well-controlled underlying diseases, no history of alcoholism, and no history of long-term use of anesthetics or sedatives;

(III) Intervention methods: studies should contain at least 2 compare groups, including an experimental group that was treated with dexmedetomidine combining with anesthetic drugs (e.g., puff, bupivacaine, or sevoflurane), and a control group that was treated with other sedatives (e.g., fentanyl or midazolam) combined anesthesia, unlimited anesthesia for inhalation or intravenous injection;

(IV) Outcome indicators: studies should have at least one outcome indicators.

(i) The main outcome:

* The effective rate of LM catheterization (no cough or limb flexion movement);

* The respiratory rate, heart rate, blood pressure, and mean arterial pressure (MAP) after LM catheterization.

* Coughing rate: more than 3 coughs during LMI.

(ii) The secondary outcome:

* The dose of anesthetic drugs used, the pain scale, the incidence of respiratory depression, and the proportion of analgesic used.

\section{Exclusion criteria}

Articles were excluded from the review if any of the following criteria were met: (I) the study was not a RCT; (II) the study used multiple drugs for anesthesia; (III) the experiments used animals (e.g., dogs, monkeys, or rats) as study subjects; and/or (IV) the article did not refer to the outcome indicators, or the data could not be extracted.

\section{Literature search strategy}

The following database were searched: Embase (January 2000-September 2021), PubMed (January 2000-September 2021), Cochrane (January 2000-September 2021), and Web of Science (January 2000-September 2021). Under the search method, a keyword rapid search was conducted using the following input keywords:

[Dexmedetomidine] AND [Laryngeal mask/Laryngeal intubation/LMI] OR [Anesthesia induction]

\section{Literature selection and data extraction}

Two researchers independently screened the articles. If any 
inconsistency arose in the process, a 3rd person was invited to discuss the issue with the researchers to determine whether the article should be included. Excel was used to extract the data. The extracted contents included: (I) basic article data: publication time, author, and region; (II) characteristics of the study subjects: patient grouping, grouping method, age, gender, disease, and type of surgery; (III) the intervention method: anesthesia method and anesthetic dosage; (IV) the outcome data: respiratory rate, effective rate of LM catheterization, blood pressure, and heart rate. In the process of data extraction, if different articles used different units for the same indicator, data conversion was performed, and the unified units were used for the synthesis analysis.

\section{Risk of bias and literature quality}

The risk of bias and the quality of the articles were analyzed using the Jadad scale. The following aspects were considered: the randomization scheme and its concealment, blindness, withdrawal, and loss of follow-up cases. Articles were given a score of $0-5$ points; a score $<3$ was considered low quality.

\section{Statistical analysis}

The following statistical methods were used: (I) Stata 16.0 was used as the analysis tool, and the statistical results were presented in a forest plot; (II) the $\mathrm{I}^{2}$ test was used to analyze the heterogeneity among different studies, and the $\mathrm{Q}$ test was used. An $\mathrm{I}^{2}<50 \%$ or a $\mathrm{P} \geq 0.1$ indicated no statistical significance in the heterogeneity [i.e., no (or acceptable) heterogeneity among the articles]; (III) the variables of this study, including the respiratory rate, heart rate, blood pressure and MAP, were continuous variables, which were expressed by the standardized mean difference (SMD); while the effective rate of LM catheterization was a binary variable, which was expressed by the odds ratio (OR). Both of these were expressed with a $95 \%$ confidence interval (CI). A $\mathrm{P}<0.05$ was considered statistically significant; (IV) for each outcome indicator, the data from all the articles reporting the indicator were combined for the statistical analysis; a comprehensive analysis was not performed if the number of reports was $<3$; (V) if there was no statistical heterogeneity among the articles, a fixed-effects model was adopted, and if there was heterogeneity, a random-effects model was adopted; (VI) heterogeneity survey: the caseby-case elimination method was adopted to determine the heterogeneity among the articles; (VII) sensitivity analysis: if the results of the fixed-effects model was not significantly different from that of the random-effects model, the results were stable; (VIII) a funnel plot was used to express the publication bias.

\section{Results}

\section{Literature screening results and characteristics of the included articles}

In this search, 352 articles were initially retrieved and reviewed. Ultimately, 7 articles with a total of 410 patients were included in the meta-analysis (see Figure 1). The basic characteristics of the articles are set out in Table 1.

\section{Analysis results}

\section{Effective rate of LMA catheterization}

Five articles $(8,10,11,12,14)$, comprising a total of 300 patients, reported the effective rate of laryngeal canal. The number of patients in the dexmedetomidine group and control group was 152 and 148, respectively. As there was no statistical heterogeneity between the articles $\left(\mathrm{I}^{2}=0 \%\right.$, $\mathrm{P}=0.999)$, the fixed-effects Mantel-Haenszel model was used. The analysis showed that the effective rate of LM catheterization induced by dexmedetomidine-assisted sedation was superior to that of the control group (OR $=1.10,95 \%$ CI: $0.78,1.53)$, but there was no statistically significant difference between the 2 groups $(Z=0.533$, $\mathrm{P}=0.594$; see Figure 2).

\section{Respiratory rate after induction of anesthesia}

Three articles $(8,10,11)$ (comprising 206 patients) examined the respiratory rate $5 \mathrm{~min}$ after the induction of anesthesia after LMA catheterization. The number of patients included in the dexmedetomidine group and control group was 103 and 103 , respectively. As there was statistical heterogeneity between the articles $\left(\mathrm{I}^{2}=94.9 \%, \mathrm{P}=0.000\right)$, the randomeffects inverse variance model was used for merging and the analysis. The respiratory rate of the dexmedetomidine group at $5 \mathrm{~min}$ after dexmedetomidine catheterization was higher than that of the control group (SMD $=3.17,95 \% \mathrm{CI}$ : $1.38,4.96)$, and the difference was statistically significant $(\mathrm{Z}=3.476, \mathrm{P}=0.001$; see Figure 3$)$.

\section{Heart rate after induction of anesthesia}

Four articles $(8-10,13)$ (comprising 236 patients) compared 


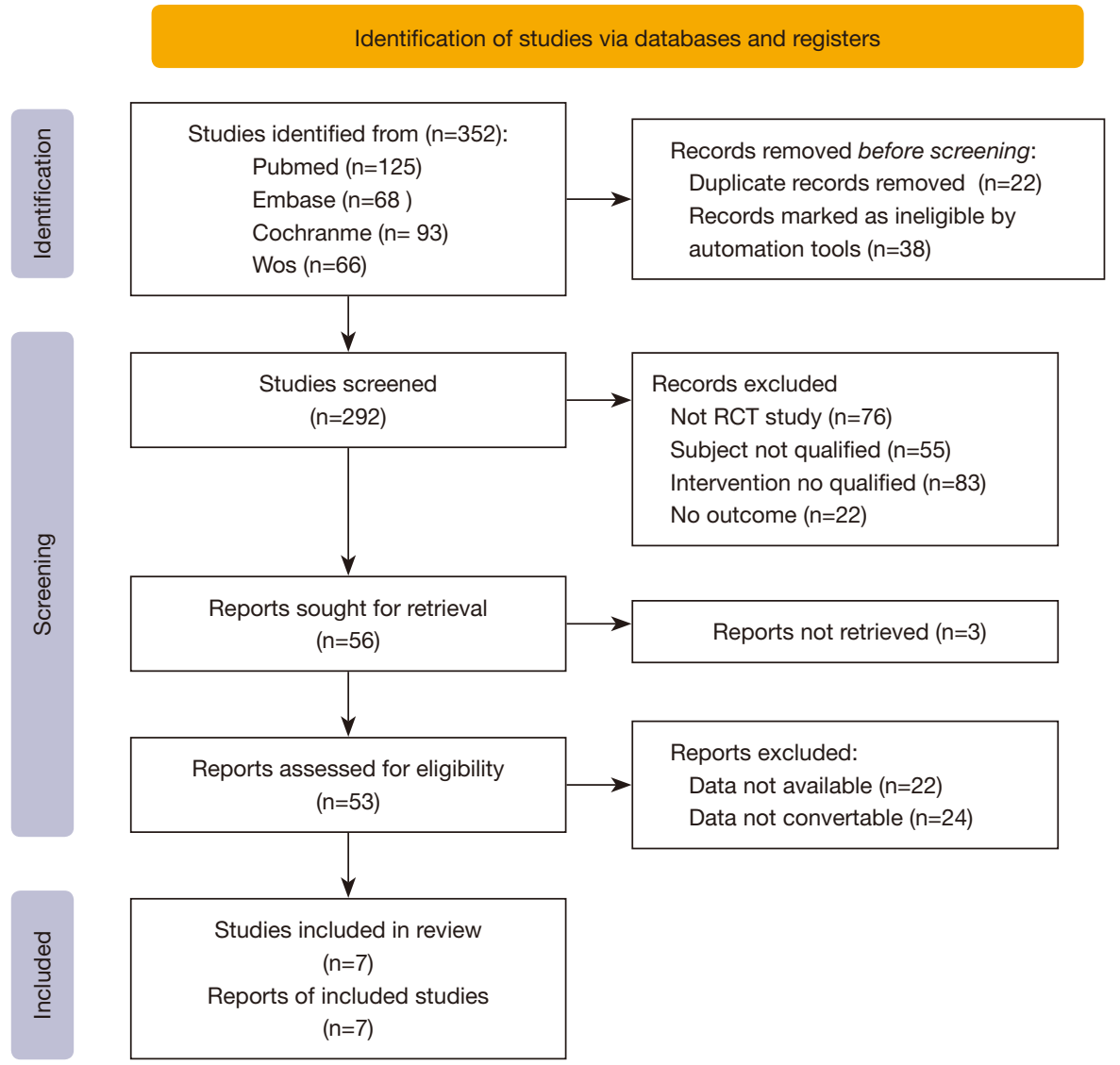

Figure 1 Flow chart of selection and inclusion.

the heart rate at $1 \mathrm{~min}$ after $\mathrm{LM}$ catheterization. The number of patients in the dexmedetomidine group and control group was 118 and 118, respectively. As there was statistical heterogeneity between the articles $\left(\mathrm{I}^{2}=77.4 \%\right.$, $\mathrm{P}=0.004)$, the random-effects inverse variance model was used for the combined analysis. The heart rate of the dexmedetomidine group at $1 \mathrm{~min}$ after dexmedetomidine catheterization was significantly lower than that of the control group (SMD $=-1.31,95 \% \mathrm{CI}:-1.91,-0.71$ ), and the difference was statistically significant $(\mathrm{Z}=-4.255, \mathrm{P}=0.000$; see Figure 4).

\section{MAP after induction of anesthesia}

Three articles $(9,10,13)$ (comprising 184 patients) compared the MAP at $1 \mathrm{~min}$ after LM catheterization. The number of patients in the dexmedetomidine group and control group was 92 and 92, respectively. As there was statistical heterogeneity among the articles $\left(\mathrm{I}^{2}=81.9 \%, \mathrm{P}=0.004\right)$, the random-effects inverse variance model was used for the combined analysis. The MAP of the dexmedetomidine group at $1 \mathrm{~min}$ after dexmedetomidine catheterization was lower than that of the control group $(\mathrm{SMD}=-0.24,95 \% \mathrm{CI}$ : $-0.94,0.45)$, but the difference between the 2 groups was not statistically significant $(\mathrm{Z}=-0.684, \mathrm{P}=0.494$; see Figure 5).

\section{Coughing rate during induction of anesthesia}

Three articles $(8,12,14)$ (comprising 146 patients) compared the coughing count at during LM catheterization. The number of patients in the dexmedetomidine group and control group was 75 and 71 respectively. No statistical heterogeneity among the articles $\left(\mathrm{I}^{2}=0 \%, \mathrm{P}=0.651\right)$, the fixed-effects Mantel-Haenszel mode was used for the combined analysis. The coughing count rate of the dexmedetomidine group was lower than that of the control group $(\mathrm{OR}=0.36,95 \% \mathrm{CI}: 0.15,0.86)$, the difference between the 2 groups was statistically significant $(Z=-2.286$, $\mathrm{P}=0.022$; see Figure 6).

\section{Heterogeneity investigation}

In the synthetic analysis of the respiratory rate, there was 
Table 1 Basic characteristics, intervention methods, outcome measures, and Jadad scores of included articles

\begin{tabular}{|c|c|c|c|c|c|c|c|}
\hline Author & Year & Study subjects & $\begin{array}{l}\text { Number of } \\
\text { samples }\end{array}$ & Age (years) & Anesthesia induction method & Outcome measures & $\begin{array}{l}\text { Jadad } \\
\text { score }\end{array}$ \\
\hline $\begin{array}{l}\text { Uzümcügil F } \\
\text { et al. (8) }\end{array}$ & 2008 & $\begin{array}{l}\text { Patients with urological } \\
\text { surgery }\end{array}$ & $52(26 / 26)$ & $26-65$ & $\begin{array}{l}\text { D: Dexmedetomidine + } \\
\text { Prednisone; C: Fentanyl + } \\
\text { Propofol }\end{array}$ & $\begin{array}{l}\text { Respiratory rate, effective } \\
\text { rate of LM catheterization, } \\
\text { blood pressure, heart rate }\end{array}$ & 5 \\
\hline $\begin{array}{l}\text { Guo F } \\
\text { et al. (9) }\end{array}$ & 2020 & $\begin{array}{l}\text { Patients undergoing } \\
\text { thoracic surgery for } \\
\text { breast cancer }\end{array}$ & $60(30 / 30)$ & $18-65$ & $\begin{array}{l}\text { D: Ropivacaine + } \\
\text { Dexmedetomidine + Propofol; } \\
\text { C: Ropivacaine + Propofol }\end{array}$ & $\begin{array}{l}\text { Propofol dosage, } \\
\text { MAP, heart rate, blood } \\
\text { pressure, } \mathrm{SpO}_{2}\end{array}$ & 4 \\
\hline $\begin{array}{l}\text { Choudhary J } \\
\text { et al. (10) }\end{array}$ & 2019 & $\begin{array}{l}\text { Patients undergoing LM } \\
\text { intubation }\end{array}$ & $74(37 / 37)$ & $18-65$ & $\begin{array}{l}\text { D: Dexmedetomidine + } \\
\text { Propofol; C: Fentanyl + } \\
\text { Propofol }\end{array}$ & $\begin{array}{l}\text { LM catheterization } \\
\text { efficiency, MAP, heart rate, } \\
\text { blood pressure, incidence } \\
\text { of hypertension, pain rate, } \\
\text { respiratory rate }\end{array}$ & 5 \\
\hline $\begin{array}{l}\text { Ramaswamy } \\
\mathrm{AH} \text { et al. (11) }\end{array}$ & 2015 & $\begin{array}{l}\text { Patients undergoing LM } \\
\text { intubation }\end{array}$ & $80(40 / 40)$ & $18-65$ & $\begin{array}{l}\text { D: Dexmedetomidine + } \\
\text { Propofol; C: Fentanyl + } \\
\text { Propofol }\end{array}$ & $\begin{array}{l}\text { LM catheterization } \\
\text { efficiency, blood } \\
\text { pressure, heart rate, MAP, } \\
\text { respiratory rate }\end{array}$ & 4 \\
\hline $\begin{array}{l}\text { Nellore SS } \\
\text { et al. (12) }\end{array}$ & 2016 & $\begin{array}{l}\text { Patients undergoing } \\
\text { elective surgery under } \\
\text { general anesthesia }\end{array}$ & $60(30 / 30)$ & $18-65$ & $\begin{array}{l}\text { D: Dexmedetomidine + } \\
\text { Propofol; C: Fentanyl + } \\
\text { Propofol }\end{array}$ & $\begin{array}{l}\text { Effective rate of LM tube } \\
\text { insertion }\end{array}$ & 5 \\
\hline $\begin{array}{l}\text { El Shamaa } \\
\text { HA et al. (13) }\end{array}$ & 2014 & $\begin{array}{l}\text { Children undergoing } \\
\text { lower abdominal and } \\
\text { perineal surgery }\end{array}$ & $50(25 / 25)$ & $1-5$ & $\begin{array}{l}\text { D: Dexmedetomidine + } \\
\text { Bupivacaine; C: Morphine + } \\
\text { Bupivacaine }\end{array}$ & $\begin{array}{l}\text { Blood pressure, heart } \\
\text { rate, MAP, incidence of } \\
\text { adverse reactions }\end{array}$ & 4 \\
\hline $\begin{array}{l}\text { Savla JR } \\
\text { et al. (14) }\end{array}$ & 2014 & $\begin{array}{l}\text { Children undergoing } \\
\text { elective surgery }\end{array}$ & $34(19 / 15)$ & $1-6$ & $\begin{array}{l}\text { D: Intravenous } \\
\text { Dexmedetomidine + } \\
\text { Sevoflurane; C: Oral } \\
\text { Midazolam + Sevoflurane }\end{array}$ & $\begin{array}{l}\text { Effective rate of LMA } \\
\text { catheterization, RSS } \\
\text { score, incidence of } \\
\text { adverse reactions }\end{array}$ & 4 \\
\hline
\end{tabular}

D represents the dexmedetomidine group; C represents the control group; LM, laryngeal mask; MAP, mean arterial pressure; LMA, laryngeal mask airway; RSS, Ramsay Sadation Scale.

\begin{tabular}{|c|c|c|c|}
\hline Study (year) & & $\begin{array}{l}\text { Odds ratio } \\
(95 \% \mathrm{Cl})\end{array}$ & $\begin{array}{c}\% \\
\text { Weight }\end{array}$ \\
\hline Uzümcügil F et al. [8] (2008) & & $1.14(0.51,2.54)$ & 17.30 \\
\hline Choudhary J et al. [10] (2019) & & $1.10(0.56,2.14)$ & 25.37 \\
\hline Ramaswamy AH et al. [11] (2015) & & $1.06(0.56,2.00)$ & 28.31 \\
\hline Nellore SS et al. [12] (2016) & & $1.17(0.55,2.49)$ & 19.28 \\
\hline Savla JR et al. [14] (2016) & & $0.96(0.32,2.93)$ & 9.73 \\
\hline Overall, $\mathrm{MH}\left(\mathrm{I}^{2}=0.0 \%, \mathrm{P}=0.999\right)$ & & $1.10(0.78,1.53)$ & 100.00 \\
\hline
\end{tabular}

NOTE: weights are from mantel-haenszel model

Figure 2 Analysis of the effective rate of dexmedetomidine-assisted anesthesia induction for LMA catheterization. LMA, laryngeal mask airway.

significant heterogeneity among the articles $(8,10,11)$, but after excluding the article (8), there was no heterogeneity in the remaining 2 articles. The patients included in the article (8) were all undergoing urological surgery, while the other 2 articles did not specify the surgery type, which might be the source of the heterogeneity. However, in the synthetic analysis of the heart rate, after 4 articles $(8-10,13)$ were excluded $(13)$, there was no heterogeneity in 


\begin{tabular}{|c|c|c|c|}
\hline Study (year) & & Effect $(95 \% \mathrm{Cl})$ & $\begin{array}{c}\% \\
\text { Weight }\end{array}$ \\
\hline Uzümcügil F et al. [8] (2008) & & $6.08(4.77,7.39)$ & 30.20 \\
\hline Choudhary J et al. [10] (2019) & $\rightarrow$ & $1.58(1.05,2.10)$ & 34.98 \\
\hline Ramaswamy AH et al. [11] (2015) & & $2.24(1.68,2.80)$ & 34.82 \\
\hline Overall, $\mathrm{DL}\left(\mathrm{I}^{2}=94.9 \%, \mathrm{P}=0.000\right)$ & & $3.17(1.38,4.96)$ & 100.00 \\
\hline
\end{tabular}

NOTE: weights are from random-effects model

Figure 3 Comparison of respiratory rate during induction of anesthesia between dexmedetomidine and other adjunctive modalities.

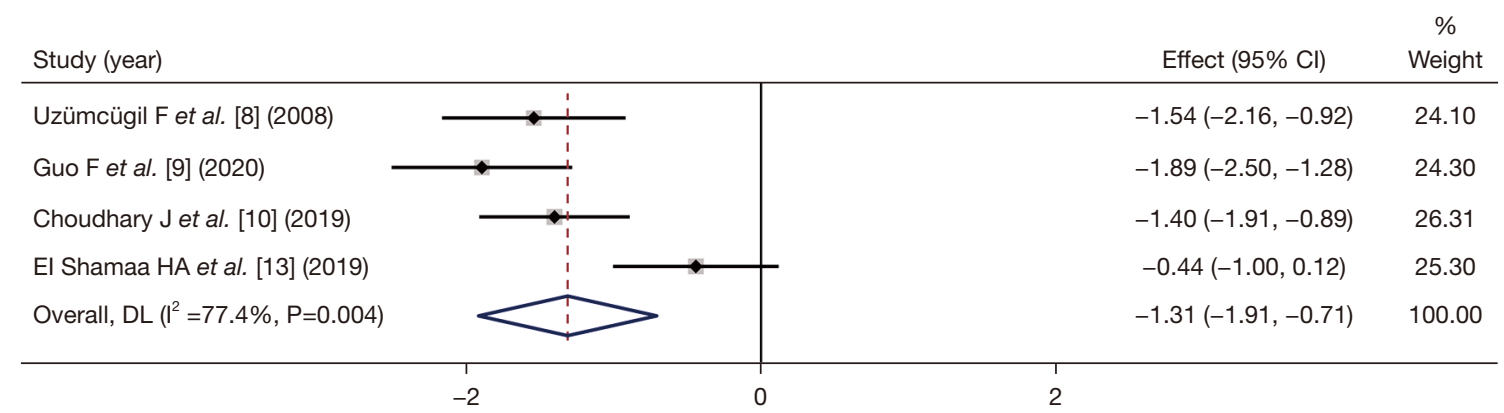

NOTE: weights are from random-effects model

Figure 4 Comparison of heart rate during induction of anesthesia with dexmedetomidine and other adjunctive modalities.

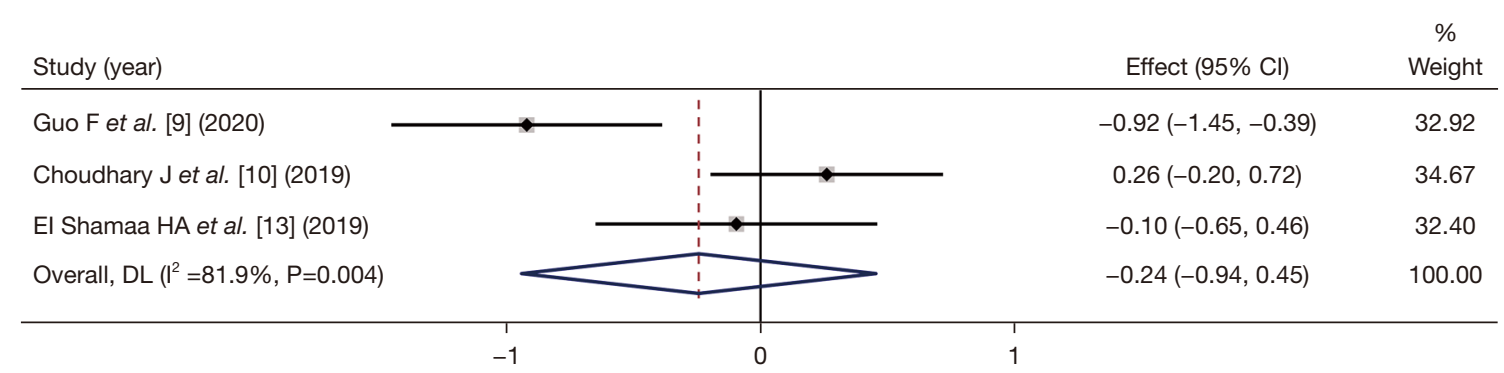

NOTE: weights are from random-effects model

Figure 5 Comparison of MAP during induction of anesthesia with dexmedetomidine and other adjunctive modalities. MAP, mean arterial pressure.

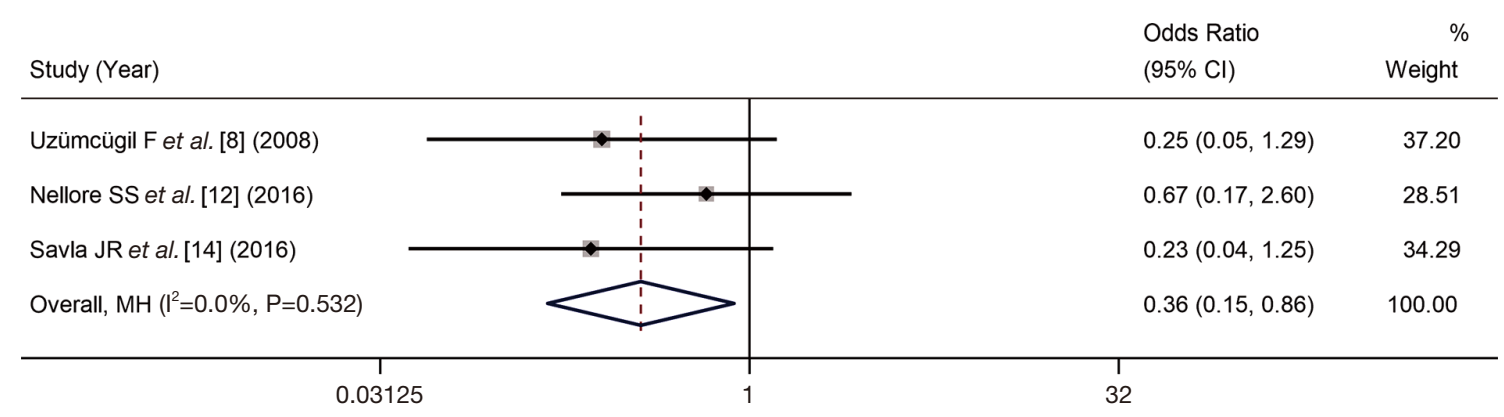

NOTE: weights are from mantel-haenszel model

Figure 6 Comparison of coughs count during induction of anesthesia with dexmedetomidine and other adjunctive modalities. 
the articles, which may be related to the fact that the study objects of the study (13) were children, while the study objects of the other studies were adults.

\section{Sensitivity analysis}

In the synthetic analysis of the effective rate of LM catheterization, there was no heterogeneity among the articles, and the results of the fixed-effects model were similar to those of the random-effects model, which indicated that the synthetic analysis results were more stable.

\section{Analysis of publication bias}

As the number of the included articles in each analysis was too small, no publication bias analysis was conducted.

\section{Discussion}

The study subjects of the 7 articles included in this study were all patients undergoing general anesthesia with LM catheterization. The meta-analysis results showed that when dexmedetomidine was used as the auxiliary inducer, adverse reactions, such as limb movement, coughing, and respiratory depression, occurred less during the process. The success rate and effective rate of LM catheterization were higher than those of fentanyl, morphine, oral midazolam and other drugs. The respiratory rate during anesthesia induction was significantly higher than that of other adjuvants, while the heart rate was lower than that of other adjuvants. The MAP was not significantly different from other drugs.

Dexmedetomidine is an $\alpha 2$ receptor agonist with good sedative, anxiolytic, and analgesic effects, it can produce a sedative state similar to physiological sleep, which reduces the possibility of coughing and limb movements during LM catheterization, and is better than other sedative drugs (15). Awake intubation is an adverse stimulation, the postoperative memory of this process will affect the psychological state of patients, and even cause physical and mental damage to patients, patients in dexmedetomidine have better sedative effect, which is of great significance for the comfort of the intubation process (16).

In addition, a previous study (17) showed that dexmedetomidine-assisted induction anesthesia significantly reduced the dosage required for anesthesia induction. Kunisawa et al. (18) pointed out that dexmedetomidine reduced the possibility of respiratory depression in patients who were awake during catheterization. Hill et al. (19) found that intravenous fentanyl had a stronger effect on respiratory depression than other anesthetic drugs. In this meta-analysis, 3 articles $(8,10,11)$ reported on changes in the respiratory rate of patients $1 \mathrm{~min}$ to $15 \mathrm{~min}$ after LM catheterization, and all 3 studies used fentanyl sedation in the control group. During anesthesia induction, the respiratory rate of patients in the control group was lower than that of patients in the dexmedetomidine group. A study (13) counted the number of cases of respiratory depression $\left(\mathrm{SPO}_{2}<95 \%\right)$, and found 0 cases in the dexmedetomidine group, and $<2$ cases in the fentanyl group (the total number of cases in both groups was 25); thus, dexmedetomidine produced fewer adverse reactions of respiratory depression during anesthesia induction.

It was also found that patients who received dexmedetomidine had a lower heart rate after LM tube insertion than those who received other sedative drugs. Study by Chen $e t a l$. (20) has suggested that dexmedetomidine may be associated with adverse reactions, such as bradycardia and hypotension. However, in this study, dexmedetomidine did not differ from fentanyl in terms of the adverse reactions of hypotension and bradycardia [e.g., the incidence rate of hypotension was 0 in both groups in the literature (13)]. Due to the effect of dexmedetomidine on hemodynamics, a study applied dexmedetomidine in the induction of surgical anesthesia in elderly patients with hypertension, the results show that the incidence of postoperative myocardial injury is less and the safety is higher than that of other drug agents (21).

The articles included in the meta-analysis showed certain heterogeneity. Notably, the source of heterogeneity may be related to the age, disease, and surgery type. In addition, it is important to classify the dose of dexmedetomidine used in the intervention method, as the results caused by different doses may differ (22). For example, Zhou et al. (23) found that the incidence of coughing in patients during the induction of anesthesia was more effectively reduced in patients administered $0.6 \mathrm{mcg} / \mathrm{kg}$ of dexmedetomidine by intravenous drip than patients administered $0.9 \mathrm{mcg} / \mathrm{kg}$ of dexmedetomidine by drip. $\mathrm{Xu}$ et al. (24) compared 2 to $1 \mu \mathrm{g} / \mathrm{kg}$ of nasal dexmedetomidine in sevoflurane inhalation in children placed under general anesthesia, and found that $2 \mu \mathrm{g} / \mathrm{kg}$ nasal dexmedetomidine reduced the success rate of LMA placement in children. A RCT conducted by Sharma et al. (25) compared the dose of 1 and $0.5 \mu \mathrm{g} / \mathrm{kg}$ dexmedetomidine in the anesthesia induction of adults LMI, the results showed that both the doses of 1 and $0.5 \mu \mathrm{g} / \mathrm{kg}$ dexmedetomidine were equally effective, but adverse effects of hypotension and bradycardia were less for $0.5 \mu \mathrm{g} / \mathrm{kg}$. 


\section{Conclusions}

Seven articles were included in this meta-analysis. The meta-analysis showed that dexmedetomidine had a good sedative effect in the induction of general anesthesia with LM catheterization, improved the success rate of LM placement, reduced adverse reactions, such as coughing and limb movement, and reduced the rate of respiratory and circulatory transplantation. However, more articles need to be included to examine the role of heart rate and blood pressure.

\section{Acknowledgments}

Funding: None.

\section{Footnote}

Reporting Checklist: The authors have completed the PRISMA reporting checklist. Available at https://dx.doi. org/10.21037/apm-21-2971

Conflicts of Interest: All authors have completed the ICMJE uniform disclosure form (available at https://dx.doi. org/10.21037/apm-21-2971). The authors have no conflicts of interest to declare.

Ethical Statement: The authors are accountable for all aspects of the work in ensuring that questions related to the accuracy or integrity of any part of the work are appropriately investigated and resolved.

Open Access Statement: This is an Open Access article distributed in accordance with the Creative Commons Attribution-NonCommercial-NoDerivs 4.0 International License (CC BY-NC-ND 4.0), which permits the noncommercial replication and distribution of the article with the strict proviso that no changes or edits are made and the original work is properly cited (including links to both the formal publication through the relevant DOI and the license). See: https://creativecommons.org/licenses/by-nc-nd/4.0/.

\section{References}

1. Gehrke T, Hackenberg S, Steinhübel B, et al. Laryngeal mask versus intubation for adenoidectomies in children: Analysis of 1,500 operations. Laryngoscope 2019;129:E383-8.
2. Kendall MC. Laryngeal mask airway as a rescue device for failed endotracheal intubation. Eur J Emerg Med 2019;26:73.

3. Wong TH, Critchley LA, Lee A, et al. Fentanyl dosage and timing when inserting the laryngeal mask airway. Anaesth Intensive Care 2010;38:55-64.

4. Makkar JK, Ghai B, Bhardwaj N, et al. Minimum alveolar concentration of desflurane with fentanyl for laryngeal mask airway removal in anesthetized children. Paediatr Anaesth 2012;22:335-40.

5. He L, Wang X, Zheng S, et al. Effects of dexmedetomidine infusion on laryngeal mask airway removal and postoperative recovery in children anaesthetised with sevoflurane. Anaesth Intensive Care 2013;41:328-33.

6. Almeida AN, Tavares C, Tibano A, et al. Dexmedetomidine for awake craniotomy without laryngeal mask. Arq Neuropsiquiatr 2005;63:748-50.

7. Ibacache ME, Muñoz HR, Brandes V, et al. Single-dose dexmedetomidine reduces agitation after sevoflurane anesthesia in children. Anesth Analg 2004;98:60-3.

8. Uzümcügil F, Canbay O, Celebi N, et al. Comparison of dexmedetomidine-propofol vs. fentanyl-propofol for laryngeal mask insertion. Eur J Anaesthesiol 2008;25:675-80.

9. Guo F, Chen H, Cai X, et al. Effects of dexmedetomidine as an adjuvant in thoracic paravertebral block on EC50 of propofol for successful laryngeal mask insertion: a randomized controlled trial. Ann Transl Med 2020;8:1480.

10. Choudhary J, Prabhudesai A, Datta C. Dexmedetomidine with propofol versus fentanyl with propofol for insertion of Proseal laryngeal mask airway: A randomized, doubleblinded clinical trial. J Anaesthesiol Clin Pharmacol 2019;35:368-72.

11. Ramaswamy AH, Shaikh SI. Comparison of dexmedetomidine-propofol versus fentanyl-propofol for insertion of laryngeal mask airway. J Anaesthesiol Clin Pharmacol 2015;31:217-20.

12. Nellore SS, Waychal AD, Rustagi PS. Comparison of Dexmedetomidine-Propofol versus Fentanyl-Propofol on Insertion Conditions of Proseal Laryngeal Mask Airway. J Clin Diagn Res 2016;10:UC06-9.

13. El Shamaa HA, Ibrahim M. A comparative study of the effect of caudal dexmedetomidine versus morphine added to bupivacaine in pediatric infra-umbilical surgery. Saudi J Anaesth 2014;8:155-60.

14. Savla JR, Ghai B, Bansal D, et al. Effect of intranasal dexmedetomidine or oral midazolam premedication on sevoflurane EC50 for successful laryngeal mask airway 
placement in children: a randomized, double-blind, placebo-controlled trial. Paediatr Anaesth 2014;24:433-9.

15. Yao Y, Qian B, Lin Y, et al. Intranasal dexmedetomidine premedication reduces minimum alveolar concentration of sevoflurane for laryngeal mask airway insertion and emergence delirium in children: a prospective, randomized, double-blind, placebo-controlled trial. Paediatr Anaesth 2015;25:492-8.

16. Sato M, Shirakami G, Tazuke-Nishimura M, et al. Effect of single-dose dexmedetomidine on emergence agitation and recovery profiles after sevoflurane anesthesia in pediatric ambulatory surgery. J Anesth 2010;24:675-82.

17. Yoo JY, Kwak HJ, Kim YB, et al. The effect of dexmedetomidine pretreatment on the median effective bolus dose of propofol for facilitating laryngeal mask airway insertion. J Anesth 2017;31:11-7.

18. Kunisawa T, Nagashima M, Hanada S, et al. Awake intubation under sedation using target-controlled infusion of dexmedetomidine: five case reports. J Anesth 2010;24:789-92.

19. Hill R, Santhakumar R, Dewey W, et al. Fentanyl depression of respiration: Comparison with heroin and morphine. Br J Pharmacol 2020;177:254-66.

20. Chen Z, Shao DH, Ma XD, et al. Dexmedetomidine aggravates hypotension following mesenteric traction during total gastrectomy: a randomized controlled trial. Ann Saudi Med 2020;40:183-90.

Cite this article as: Ju Q, Xiao Z, Sun W, Zhu M, Lv P. The anesthesia induction effect of dexmedetomidine in patients undergoing laryngeal mask intubation: a systematic review and meta-analysis of 7 RCTs. Ann Palliat Med 2021;10(12):12358-12366. doi: 10.21037/apm-21-2971
21. Du X, Yu J, Mi W. The effect of dexmedetomidine on the perioperative hemodynamics and postoperative cognitive function of elderly patients with hypertension: Study protocol for a randomized controlled trial. Medicine (Baltimore) 2018;97:e12851.

22. Kwak HJ, Min SK, Yoo JY, et al. The median effective dose of dexmedetomidine for laryngeal mask airway insertion with propofol $2.0 \mathrm{mg} / \mathrm{kg}$. Acta Anaesthesiol Scand 2014;58:815-9.

23. Zhou W, Zhang D, Tian S, et al. Optimal dose of pretreated-dexmedetomidine in fentanyl-induced cough suppression: a prospective randomized controlled trial. BMC Anesthesiol 2019;19:89.

24. Xu J, Deng XM, Wei LX, et al. Effects of Two Intranasal Dexmedetomidine Doses as Premedication on Sevoflurane EC50 for Successful Laryngeal Mask Airway Placement in Children. Zhongguo Yi Xue Ke Xue Yuan Xue Bao 2016;38:627-31.

25. Sharma N, Mehta N. Therapeutic Efficacy of Two Different Doses of Dexmedetomidine on the Hemodynamic Response to Intubation, the Intubating Conditions, and the Effect on the Induction Dose of Propofol: A Randomized, Double-Blind, PlaceboControlled Study. Anesth Essays Res 2018;12:566-71.

(English Language Editor: L. Huleatt) 